This paper was accepted to Journal of Cleaner Production, Impact Factor 7.246, on $27^{\text {th }}$ November 2020, in this (revised) version.

\title{
Are those really transformative learning outcomes? Validating the relevance of a reliable process
}

${ }^{*}$ Marie K. Harder,b, Felix O. Dike ${ }^{a}$, Firooz Firoozmand ${ }^{b}$, Nicole des Bouvrie ${ }^{a}$, Rachel J. Masika $^{c}$

a) Department of Environmental Science and Engineering, Fudan University, 2205 Songhu Road, Yang Pu district, Shanghai, PR China 200438

b) School of Computing, Engineering and Mathematics, University of Brighton, Lewes Road, Brighton, UK BN2 4GJ

c) Centre for Teaching and Learning, University of Brighton, Watson Building, Falmer Campus, UK BN1 9PH

Corresponding author: *Marie K. Harder, Department of Environmental Science and Engineering, Fudan University, 2205 Songhu Road, Yang Pu district, Shanghai, PR China 200438

Phone: +86 15221626760 email:m.k.harder@brighton.ac.uk 


\begin{abstract}
Transformative learning is considered a cornerstone for advances in sustainability, because transformative shifts in perspective will be necessary for humankind to transition towards it. The theory of transformative learning $(T L)$ has been considered in hundreds of applied studies in diverse fields, yet it remains descriptive and unable to prescribe which conditions and processes could reliably produce TL outcomes. Here an in-depth case study is used to investigate a candidate process from another field and unknown to TL researchers (called WeValue InSitu) which has been reported to regularly produce some forms of informally denoted 'transformative outcomes'. The goal is to determine if these formally qualify, because this would imply the standard WeValue InSitu process could be a reliable way to produce, and investigate, TL and TL outcomes (TLOs). Using grounded thematic open-coding of full transcripts of three sets of post-event interviews, compared against statements made prior to the event, it is shown unambiguously that four outcomes have formal TL nature, as shifts in meaning schemes, one of which developed into a wider shift of meaning perspective over three weeks. These findings indicate that the WeValue InSitu process can likely produce TLOs regularly and identifiably, offering a 'pedagogical laboratory' which can be used for systematic studies to link its subprocesses in detail to the TL outcomes it produces, allowing step-wise progress in theorybuilding. It also indicates that WeValue InSitu can be prescriptively applied, within its limitations such as maximum group sizes and specialist facilitators, to trigger TL in local groups of villagers, governance officers, environmental enthusiasts, community-based organizations and/or government committees, to become more focused and self-aware and more mobilized towards sustainability actions. This study thus opens the door to new research agenda in theory-building and applications of TL towards sustainability.
\end{abstract}

\title{
Keywords:
}

transformative learning outcomes; WeValue Insitu; sustainability learning; transformative learning theory 


\section{Introduction}

The importance of transformative learning for achieving sustainable development has been widely acknowledged in different areas such as for transforming learners into agents for sustainability (Greig and Priddle, 2019; Leal Filho et al., 2018); advancing sustainability education (Ofei-manu and Didham, 2018; Pisters et al, 2019); and as a key element of global commitments in the 2030 sustainable development agenda (UNESCO, 2017). Sustainable development requires a profound transformation of how to think and act (UNESCO, 2017, p. 5) and addressing sustainability challenges demands paradigmatic and epistemic transformative changes (Brunstein and King, 2018). Transformative Learning (TL) involves 'disorienting' processes which call into question our taken-for-granted frames of reference in order to generate beliefs and opinions that are more discriminating, robust and better validated to ourselves as a guide for our immediate and future actions (Burgelt et al. 2018).

Education for sustainable development (ESD) aims to empower learners to make informed critical decisions, and to take responsible actions for environmental integrity and economic viability with increased self-awareness for a just society for present and future generations (UNESCO, 2017, p.7). To achieve this, ESD aims to develop in individuals in formal education the skills, values, attitudes and discriminating mindsets that will empower them to be able to effect necessary change, and TL has been adopted towards that end. Didham and OfeiManu (2013, p.6) posited that "Transformative Learning is needed (as a catalyst) for realizing essential improvements in the quality of education, and for a sustainable future for all". Desired TL outcomes for sustainability include critical reflexivity, a more discriminating mindset, and raised self-awareness - competencies which empower individuals and increase their capacities as agents of change in society (UNESCO, 2017).

Such outcomes of transformative learning have been increasingly sought not only in ESD, but also in applied sustainability settings. In climate change adaptation and risk resilience, Sharpe (2016) identified TL towards sustainable behaviour among local people at community level, and called for more related research. In resource management, Diduck et al. (2012) identified important TL influences in a study of sustainable behaviour compliance from local farmers. And a recent study showed village committees transformed their perspectives and then behaviour to actively engage with production and implementation of local adaptation plans (Sethamo et al., 2019).

A conceptual basis for TL used in all the fields mentioned above is Mezirow's (1991) foundational Transformative Learning Theory (TLT). It includes 10 transformative learning processes, four classifications of possible transformative learning outcomes, and notes on the likely learning conditions required. Several critiques and variations have expanded the TLT basis (Taylor, 1998; Hoggan, 2015; O'Sullivan, 2008; Dirkx et al., 2018), but the idea has persisted of a core series of elements which are recursive and spiral in nature (Taylor, 1998), involving at least a disorienting dilemma causing critical reflection, and resulting in some nonsuperficial shift in perspective. Unfortunately, the outcomes are often defined in terms of the process, and the process in terms of the outcomes - a circular argument which is a recurring cause of confusion and a barrier to further theory-building. 
Thus, even forty years later, there is no prescriptive theory to allow the predictive production of TL: in fact, there are still major hurdles reported in even determining what the defining attributes are of transformative learning processes, outcomes and/or conditions. A very recent review (Aboytes \& Barth, 2020) of 83 applied studies which used TLT as a main framework found that the nature of TL outcomes is often unclear or unspecified (Aboytes \& Barth, 2020), even in recent approaches to evaluation (Papenfuss and Merrit, 2019; Probst et al., 2019; Brunstein et al., 2019). This is mirrored in criticisms about the unspecifiable nature of the processes which produce TL (Newman, 2012; Hoggan, 2015). And Taylor \& Snyder (2012) in their review noted that "though basic assumptions for fostering transformative learning have been accepted - for example, learner-centred teaching- there is still lack of a clear understanding of what it (TL) looks like in practice". Aboytes \& Barth's (2020) systematic review concludes: "Finally, there is a need for better methods and tools that can provide insights into the processes and outcomes of transformative sustainability learning".

This study responds to the simultaneous high demand for TL and its outcomes (TLOs) and the lack of known systematic and reliable approaches to fostering them. It does this by investigating an emerging process which appears to regularly produce TL outcomes: a process which is not known to TL researchers but is established in other fields, called WeValue InSitu. The TL outcomes it produces are not always directly towards sustainability, but often includes that direction. If the standard WeValue InSitu process can indeed reliably produce formally-identifiable TL outcomes (TLOs), then it could provide a 'pedagogical laboratory' with opportunities for replicable and systematic studies of TL processes, outputs, and conditions. This would likely lead to a step-wise improvement in understanding, identifying and conceptualizing $T L$, which are pre-requisites for the possibility of widespread applications which are in such demand for sustainability.

The WeValue family of values-based processes were originally developed with the aim to 'crystallize' the shared values of civil society groups to produce local indicators for sustainability (Burford et al., 2013). They evolved via action research (Podger et al. 2010; Podger et al., 2012) using a research-through-design approach that was practice-based (Harder \& Burford, 2018) - which means WeValue has no disciplinary theoretical underpinning but is activity-based. Early work focused on enabling groups to produce their own localized indicators (Podger et.al. (2016), and only later was it realized that the interim processes were themselves of great value, because they triggered changes in thinking. A retrospective study across eight organizations demonstrated considerable unexpected 'impacts' that were informally labelled as 'transformative' (Burford et.al., 2016). The groups were very diverse, including a: small rural NGO promoting environment in youth groups (Mexico); global organization providing online ecocourses (Costa Rica); wealth management company (Luxembourg) without explicit ethical values commitment; humanitarian aid organization with conflict-affected youth (Sierra Leone) and its global youth summit (Jordan); values-driven cosmetics company (Italy); an NGO using forum theatre training conflict resolution in schools (Germany).

The fact that outcomes informally described as 'transformational learning' were reported in such diverse contexts by the same approach suggested that it might have important 
contributions to the fields of $T L$, and that is why it is investigated in this study. We treat it here as a 'black box' and focus on validating its outcomes: analyses of its processes must wait for further studies. However, for reference, we mention that the WeValue InSitu process is conceptualised by its facilitators in terms of its four standard activities (Moreno et al., 2017; Sethamo, et.al., 2019). Activity Stage 1 is photo-elicitation of values-based storytelling (where group members select photos that resonate with what they find valuable, meaningful and worthwhile about being part of the group and then verbally present them); Activity Stage 2 triggers further deeper resonances (by reading and reflecting on a uniquely constructed 'trigger' list of related phrases used by other people); Activity Stage 3 develops inter-subjective group discussions in a particular manner, to 'crystallise' collective understandings (of what is meaningful about their activities) and to write them onto cards. Activity Stage 4 involves participants arranging their cards, physically, into a representative structure showing links between them (an example is given in Figure 1). They also give a narrative of it, usually 2-5 paragraphs. It can thus be viewed as an ethnographic approach - very different to most formal or informal education approaches.

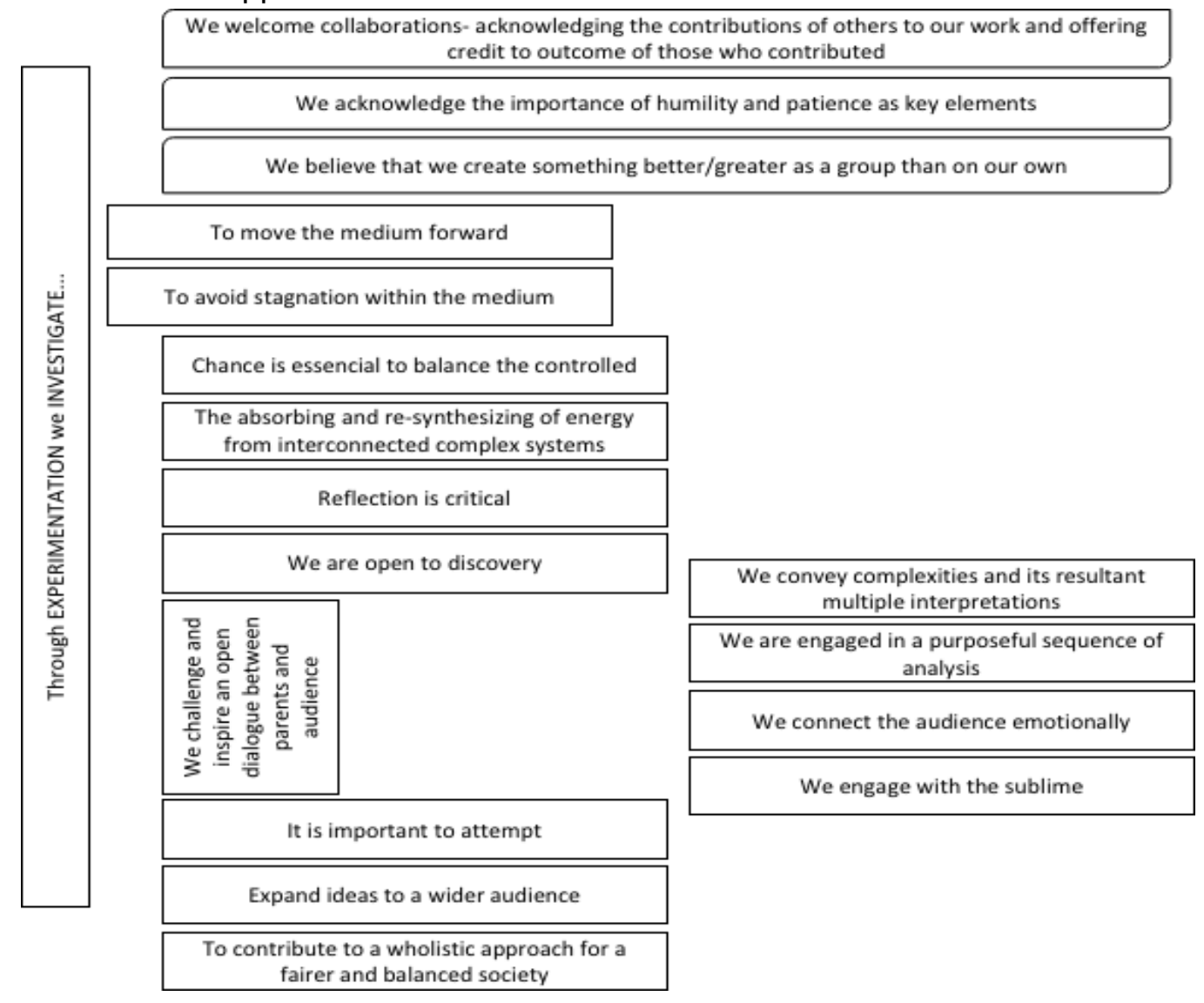

Fig. 1. An example of the main tangible output of a WeValue InSitu event lasting 3-4 hours: a framework of Local Shared Values Statements as developed one-by-one and then linked, by participants working together. Not shown, is the preamble for every statement of, "It is important to us that...". A narrative of 2-5 paragraphs to explain it is 
also produced. The statements can easily be developed into sustainability indicators.

This specific example relates to the case study reported in this paper.

In summary, there is concurrently a high demand for transformative learning outcomes (TLOs) for sustainability, and a well-documented lack of systematic or reliable approaches to produce them. This paper investigates a candidate process designed for another purpose which reports TL-like outcomes produced regularly but as an unintended by-product. If those outcomes can be confirmed as formal transformative learning outcomes (TLOs), then that process would provide a unique and much-sought 'pedagogical laboratory' for replicable and systematic studies of TL. This would lead to step-wise improvements in TL theory-building, including for prescriptive theories to optimise pragmatic activities. This in turn should lead to the acceleration of some aspects of sustainable development.

In this paper we set out the requirements for formal testing of TL nature of learning outputs as synthesised from the literature, and how we will test the candidate process in a case study. The findings are presented, including additional data used for triangulation. A discussion of the implications to education and sustainability domains is given, followed by conclusions about the new research agenda opened up by this work.

\section{Methodology}

This work focuses on the validation (or not) of the nature of the outcomes of a standard WeValue InSitu process as being transformative learning as per Mezirow's Transformative Learning Theory (TLT). First, to indicate how common the TL-like nature of WeValue InSitu might be, and its potential reliability to produce TLOs, a brief systematic literature review will collate evidence from all previously published reports.

Secondly, an in-depth case study will be used to rigorously examine one WeValue InSitu event, designed with pre-event interviews to provide broad baselines, and a series of post-event interviews to identify evidence of TLOs - i.e. shifts in meaning schemes. The chronology of the data collection events is shown in Figure 3.

Thirdly, for triangulation and counter-argument checking of the TLOs found, the postinterviews will be analysed for any allusions to particular sub-processes within the WeValue InSitu event itself which were perceived as being linked to the TLOs, using closed coding based on the ten TL processes put forward by Mezirow (2000).

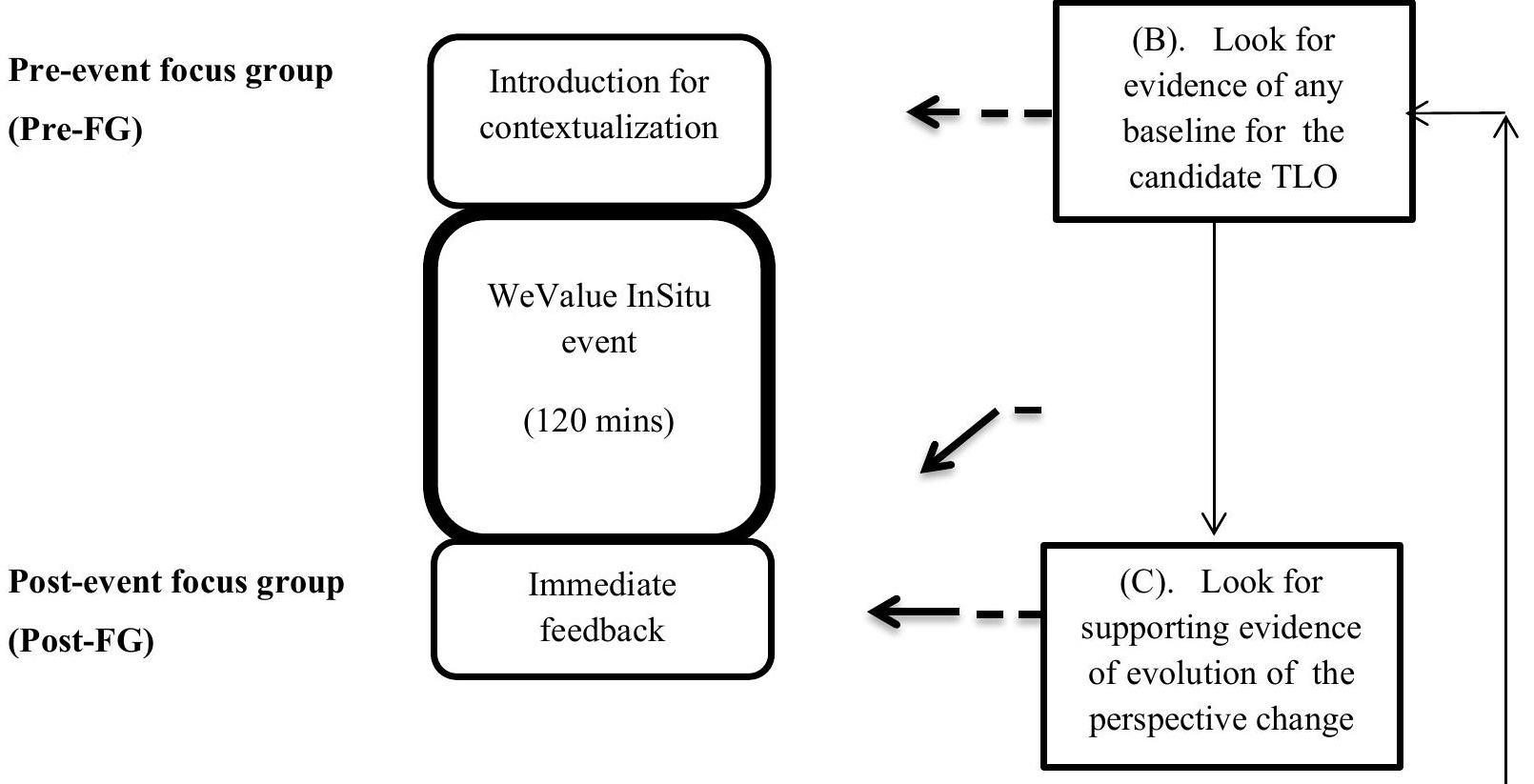




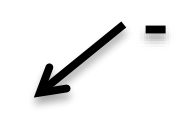

Fig.2. Chronology of data production, collection and analysis. The WeValue event is sandwiched between pre- and post-event data collections which used focus groups and interviews which were all recorded and transcribed. The analysis started at A) and ended at C).

For data collection, the pre-event statements were collected from recordings of the Introduction pre-session where individuals introduced themselves, the group, and their roles, immediately before the event. This was followed by the WeValue InSitu event itself, which is treated here as a 'black box' as it involves complex conversations and interactions and was not expected to contribute to the data needed on outcomes - it was thus not recorded. The first post-event interviews (Post-FG) were taken immediately after the event in the context of feedback on the event, followed by two further sets of post-event interviews 1 and 4 weeks later (Post-1,2).

The participants were not told that the study might focus on TLOs, to prevent bias. Informed consent obtained was for a broad research series of WeValue explorations to develop values-based approaches for crystallization of group shared values, and to better understand 'what the process was useful for'. The data is thus extracted from responses to general, openended, broad questions (e.g. about their experience of the event), and then any illustrations of potential shifts which were provided were followed up for more details. Only in the final interviews, were the participants explicitly asked to identify changes in their thinking, plans, actions or behaviour which had been triggered by the event. The exact questions can be read within the full transcripts given in Supplementary File.

The particular case was chosen for convenience by an expert who generally oversees the running of numerous such events; it did not present as anomalous in any way, and the participants had given informed consent to repeated post-interviews. The group participants were a professional artist and his team of a curator and publicist, who had worked together for four years on conceptualising and producing art that draws attention to issues of environmental justice, fairness and social justice.

For analysis, the post- interviews were transcribed and coded with open themes after several rounds of deep reading, in a grounded approach. The only search criterion was that the statements refer to some kind of impact or change (i.e. a potential TLO). The code book was thus iteratively augmented, and a final reading ensured that all themes found had been considered across all interviews. Each theme was then cross-checked against the pre-event 
interviews for related statements, which were extracted. This entire process was carried out by two independent researchers, who later discussed and resolved the (few) differences. Figure 2 shows the investigation pathways. Each instance of a 'change'/TLO which emerged, and its contextual strands of conversation, was then categorized using the formal TL Outcomes categories of Mezirow (2000) and Hoggan (2015), separately.

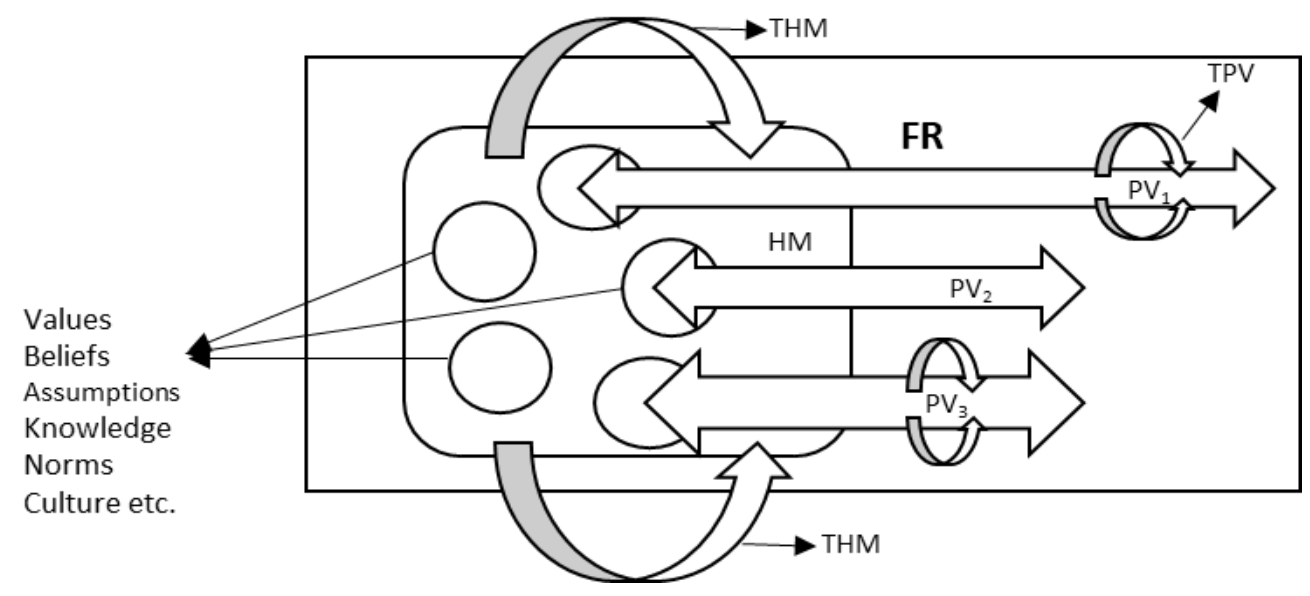

Fig.3. Transformative Learning Outcomes. Schematic representation of Mezirow's (1991) classification of Transformative Learning Outcomes. When one point of view (PV) is transformed within a Frame of Reference (FR), a Transformation in Meaning Scheme has occurred, denoted by the straight arrows. Transformations of the Habit of Mind (a.k.a. Meaning Perspective) require a more comprehensive change involving transformation of multiple points of views. THM=Transformation in Habit of Mind. TPV=Transformation in Points of View.

The analysis framework from Mezirow's Theory of TL defines two major types of transformative learning outcomes. Transformation in Meaning Schemes (a.k.a. Points of View), pertains to more narrow and specific aspects of life (Najjar et al. 2013), described by Mezirow (2000) as "immediate specific expectations, beliefs, feelings, attitudes, and judgments, that tacitly direct and shape a specific interpretation and determine how one judges, typifies objects and attributes causality". Such a shift would be about something specific.

Transformation of Perspective (a.k.a. Habit of Mind), entails becoming critically reflective of wider beliefs and assumptions, and those of others, and aware of the contexts - the source, nature and consequences of taken-for-granted beliefs (Mezirow, 2000). A shift here would likely impact on multiple meaning schemes. Figure 2 illustrates both schematically.

\section{Findings}

3.1. Evidence of previous reports of TL-like nature of WeValue outcomes

Even though 'transformational' effects were not the focus of any of the previous WeValue studies, and they were thus not described in great detail, it was possible to clearly 
identify ten case examples in five publications (extracts are given in Appendix A, with comments). Some were via self-reports, but others included third-party observations, which are rare in mainstream TL literature and thus valuable as less-subjective evidence. Categories from Hoggan (2015) of Epistemology, Worldview, and Behaviour could be identified.

\subsection{Transformative learning outcomes found, and their nature}

Four sets of TLOs emerged from the data (Tables 1,2 and Appendix B) all meeting the strict criterion of Mezirow's categorizations of Transformations in Meaning Schemes, which refers to a more-narrow shift in thinking. Categories from Hoggan (2015) of Epistemology and Behaviour could be clearly identified, with the data was rich enough to assign Hoggan (2015) variable scales $(\sqrt{ } \checkmark \checkmark)$ of depth, breadth and relative stability. In each case there are not one but several linked statements found, from pre- and post- events, which thus firmly indicate identifiable shifts.

In one of the four datasets showing a Transformation of Meaning Schemes, the postevent data indicated that the transformative effect seemed to continue (Table 3), eventually leading to a much wider Transformation of Perspectives (a wider shift typically encompassing several related meaning schemes). For example, items Pre-E (a) [initial statement expressing the initial mindset about their artwork] in Table 3 state rather narrow perspectives of the meaning of their (art) work - a form of academic and commercial communication into wider structures of society. The item Post-E a) [statement showing an initial narrow shift in the meaning of their work] is concise but much broader - pinpointing the complexities and plural interpretations as being at its heart. Item Post-E c), [ statement now showing much broader shift in the meaning of their work], mentioned one week later but referring to a group statement developed in the event, indicates a broader perspective is now actively in use - regarding the meaning of the work as a contribution towards a fair and balanced society. This perspective is now not narrow: it is an umbrella over activities of not only communication but also production and purpose of the art. The earlier statements are seen as lesser, more specific ones with this last statement as the core guiding principle across many meaning schemes: the group intends 
Table 2. Transformative Learning Outcomes emerging from the data: two sets which each link to an identifiable Transformation, as Mezirow's (1991) category of Transformed Meaning Schemes (TMS), and Hoggan (2015) classifications: Beh, Epis, and ratings using Hoggan's (2015) analytical chart $(\sqrt{ } \sqrt{ })$ (see footnotes). $\left({ }^{* *}\right)$ indicates particularly strong evidence i.e. reports via a third party or concerning actual behaviors. SM:1 refers to Supplementary Materials, Section 1.

\begin{tabular}{|c|c|}
\hline Excerpts of Data Extract (Pre-E = Pre-event); Post-E=Post Event) & Comments \\
\hline \multicolumn{2}{|c|}{ Transformation in Conceptualizing METHOD OF THE ARTIST. (TMS; Beh. /Epist.) } \\
\hline $\begin{array}{l}\text { [Pre-E] "...we are engaged on a journey where we're not entirely clear where the end is - the } \\
\text { shape of the journey - but we know we're on it and we're enjoying it and we're purposeful in } \\
\text { terms of our engagement...." (Pre-FG; Participant C; SM } 1 \text {; line 62-66) }\end{array}$ & $\begin{array}{l}\text { Statement/evidence showing a fuzzy } \\
\text { method of working }\end{array}$ \\
\hline $\begin{array}{l}\text { [Post-E] (a) "...it's so hard to find the right words to explain what it's (the WeValue InSitu event) } \\
\text { given us... it's allowed us to see the component parts of the endeavor that we're engaged } \\
\text { in...it's chopped it... it's deconstructed it and opened it up into component parts which now is } \\
\text { going to allow us to reflect on those and explore it and decide which is the more important } \\
\text { element of the practice..." (Post-FG; Participant C; SM 2; line 136-141) }\end{array}$ & $\begin{array}{l}\text { Evidence showing that participants can } \\
\text { now see component parts of the endeavor. } \\
\text { (D } \sqrt{ } \sqrt{ } ; \mathbf{B} \sqrt{ } ; \mathbf{R S}, \sqrt{ })\end{array}$ \\
\hline $\begin{array}{l}\text { [Post-E] (b) “** having a better understanding of how the creative process works... }{ }^{* *} \text { ( Post- } \\
\text { Int.1; Participant J: SM 3; line 178-179) }\end{array}$ & $\begin{array}{l}\text { Further evidence that the participants now } \\
\text { understands the creative process in a } \\
\text { different way (TMS) } \\
\text { (D } \sqrt{ } \text {; B } \sqrt{ } \sqrt{ } \text {; RS, } \sqrt{ } \sqrt{ } \text { ) }\end{array}$ \\
\hline $\begin{array}{l}\text { [Post-E] (c) "... which was consolidating the various aspects of the work, um, and the } \\
\text { function of the work and the function between the } 3 \text { of us. Um, which was very effective" } \\
\text { (Post-Int.1; Participant J; SM 3, lines } 62-65 \text { ) }\end{array}$ & $\begin{array}{l}\text { (Ditto) } \\
(\mathbf{D} \sqrt{ } ; \mathbf{B} \sqrt{ } ; \mathbf{R S}, \sqrt{ } \sqrt{ })\end{array}$ \\
\hline $\begin{array}{l}\text { [Post-E] (d) "...you came away (from the workshop) feeling much more aware of your...what's } \\
\text { the word, your process (used as noun not verb), for want of a better word; your methodology: - } \\
\text { that's the word I'm looking for - Methodologies..." (Post-Int.1, Participant J; SM 3. line 138-140) }\end{array}$ & $\begin{array}{l}\text { The participant further can now apply the } \\
\text { new work method } \\
\text { (D } \sqrt{ } \sqrt{ } \text {; } \mathbf{B} \sqrt{ } \sqrt{ } ; \mathbf{R S}, \sqrt{ } \sqrt{ } \text { ) }\end{array}$ \\
\hline
\end{tabular}




\begin{tabular}{|c|c|}
\hline $\begin{array}{l}\text { [Post-E] (e) "It (the WeValue InSitu event) did, it actually got me thinking about new projects } \\
\text { that I'm working on, and **adopting this cyclical pattern and how everything interacts." (Post- } \\
\text { Int.1; Participant J; SM 3; lines 144-145) }\end{array}$ & $\begin{array}{l}\text { Evidence participant can see the method } \\
\text { used from new point of view } \\
(\mathbf{D} \sqrt{ } \sqrt{ } ; \mathbf{B} \sqrt{ } ; \mathbf{R S}, \sqrt{ } \sqrt{ })\end{array}$ \\
\hline $\begin{array}{l}\text { [Post-E] (f) "..primarily... it made it concise writing about my methodologies, and when I write } \\
\text { down my actual methodology, I could practically order what I do and felt everything much } \\
\text { clearer, and that pretty much how I do ... like how I will handle it in the future." (Post-Int.2; } \\
\text { Participant J; SM 6, lines 19-21) }\end{array}$ & $\begin{array}{l}\text { (Ditto) } \\
\text { (D } \sqrt{ } \sqrt{ } ; \mathbf{B} \sqrt{ } ; \mathbf{R S}, \sqrt{ } \sqrt{ } \sqrt{ })\end{array}$ \\
\hline \multicolumn{2}{|l|}{ Transformation in FUNCTIONS BETWEEN US. (TMS; Beh.) } \\
\hline $\begin{array}{l}\text { [Pre-E] "We research and conceptualize (academic) work, and make work (art products). } \\
\text { (Participant C) helps.... She navigates a way into the academic structures." (Pre-FG; } \\
\text { Participant J; SM 1, lines 11-13) }\end{array}$ & $\begin{array}{l}\text { J here does not understand what } \mathbf{S} \text { does to } \\
\text { Navigate them [the team] to academics. } \\
\text { Fuzzy MS on how they work }\end{array}$ \\
\hline $\begin{array}{l}\text { [Post-E] (a) "... was consolidating the various aspects of the work, um, and the function of the } \\
\text { work and the function between the } 3 \text { of us. Um, which was very effective, I think it definitely } \\
\text { highlighted areas within the mechanism of how we work..." (Post-Int.1; Participant J; SM } 3 \text {, } \\
\text { lines 62-65) }\end{array}$ & $\begin{array}{l}\text { The Function between the participants } \\
\text { becomes highlighted (known) } \\
\text { (D } \sqrt{ } ; \mathbf{B} \sqrt{ } \text {; RS, } \sqrt{ } \sqrt{ } \text { ) }\end{array}$ \\
\hline $\begin{array}{l}\text { [Post-E] (b) "I felt much clearer with what the process was... of how we function and the making } \\
\text { of the art; it's consolidated a few things. Clarified; ordered what happens. So it was a ..., I felt } \\
\text { satisfied is probably the most relevant word". (Post-Int.1; Participant J; SM 3; 18-21) }\end{array}$ & $\begin{array}{l}\text { The process further becomes clearer } \\
\text { (D } \sqrt{ } ; \mathbf{B} \sqrt{ } \sqrt{ } \text {; } \mathbf{R S}, \sqrt{ } \sqrt{ } \text { ) }\end{array}$ \\
\hline $\begin{array}{l}\text { [Post-E] (c) "I think } 2 \text { points ... reiterated everything l've been thinking and conveying to } \\
\text { (Participant S). and (Participant C) . and also the clarification process. So. ..." (Post-Int.1, SM:3. } \\
\text { J. Lines 132-135) }\end{array}$ & $\begin{array}{l}\text { (Ditto) } \\
(\mathbf{D} \sqrt{ } ; \mathbf{B} \sqrt{ } \sqrt{ } ; \mathbf{R S}, \sqrt{ } \sqrt{ })\end{array}$ \\
\hline $\begin{array}{l}\text { [Post-E] (d) }{ }^{* *} \text { Also, when asked if he noticed change in the behavior any other participant in } \\
\text { their group, Participant A commented thus: "I think (Participant C)'s methodologies are } \\
\text { becoming more efficient. She seems to think clearer and faster...** "(Post-Int.2, SM:6, J, lines } \\
62-63)\end{array}$ & $\begin{array}{l}\text { Observed change in behavior; improved } \\
\text { methodology. } \\
(\mathbf{D} \sqrt{ } ; \mathbf{B} \sqrt{ } \sqrt{ } ; \mathbf{R S}, \sqrt{ } \sqrt{ })\end{array}$ \\
\hline
\end{tabular}


Note: Mezirow's TL classification: TMS=Transformation in Meaning Scheme, TMP= Transformation in Meaning Perspectives. Hoggan's classification: Ont. = Ontology; Beh. = Behaviour; Epist. = Epistemology, and Wv = Worldview. Scale: $(\sqrt{ } \sqrt{ }=$ highly observed $) ;(\sqrt{ } \sqrt{ }=$ moderately observed $)$ and $(\sqrt{ }=$ less observed $)$ : $D=$ Depth; $B=$ Breadth; and RS = Relative stability.

\section{Table 3}

Transformative Learning Outcomes emerging from the data: an unusual example of a Transformation in Meaning Schemes (TMS) which evolves into a Transformation in Meaning Perspective (TMP) ..... Hoggan classifications: Beh, Epis, and Wv, rated using Hoggan's analytical chart $\sqrt{ } \sqrt{ }$ (see footnotes).

\begin{tabular}{|l|l|}
\hline \multicolumn{1}{|c|}{ Excerpts of Data Extract (Pre-E = Pre event); Post-E=Post Event) } & \multicolumn{1}{|c|}{ Comments } \\
\hline \multicolumn{1}{|c|}{ Transformation in Perceiving MEANING OF THEIR WORK (TMS -> TMP; Epist, Wv.) } \\
\hline $\begin{array}{l}\text { [Pre-E] (a) "We are sort of a strategic group to promote academic and commercial environment } \\
\text { globally". (Pre-FG; Participant J. SM1; lines 8-9) }\end{array}$ & $\begin{array}{l}\text { A clear statement of initial perspective of the } \\
\text { Meaning of Our Work }\end{array}$ \\
\hline $\begin{array}{l}\text { [Pre-E] (b) "We research and conceptualize (academic) work, and make work. S... navigates a } \\
\text { way into [communicates to] the academic structures." (Pre-FG; Participant J; SM 1; lines 11-13) }\end{array}$ & (ditto) \\
\hline $\begin{array}{l}\text { [Post-E] (a) "Yeah sure...this is what we do: we convey complexities and its resultant multiple } \\
\text { interpretations. ..." (Post-FG; Participant S; SM 2; line 10-13) }\end{array}$ & $\begin{array}{l}\text { A deeper statement, evolved but shifted from a), } \\
\text { approximately the same scope -thus a TMS (with } \\
\text { some broadening). (D } \sqrt{ } \text {; B } \sqrt{ } \text {; RS, } \sqrt{\text { ) }}\end{array}$ \\
\hline $\begin{array}{l}\text { [Post-E] (b) "understand more clearly as a group WHO we are... therefore it [WeValue InSitu] } \\
\text { helped us to articulate what is it at the heart of our project..." (Post-Int.1; SM 5; Participant C; } \\
\text { lines 47-48; 50-51; 64-67) }\end{array}$ & $\begin{array}{l}\text { A comment implying aTLO: that they can better } \\
\text { articulate the work/ meaning. Indicates scope is } \\
\text { widening. } \\
\text { (D } \sqrt{ } ; \text {; B } \sqrt{ } \text {; RS, } \sqrt{ } \sqrt{ } \sqrt{ } \text { ) }\end{array}$ \\
\hline $\begin{array}{l}\text { [Post-E] (c) "...we came up with this phrase, which I think we all sort of agreed with... I'm going } \\
\text { to read it: 'to contribute towards achieving a holistic approach to a fair and balanced society..." } \\
\text { (Post-Int.1; SM 5; Participant C; lines 64-68) }\end{array}$ & $\begin{array}{l}\text { A wider-Scope statement of the Meaning of the } \\
\text { Work. Shifted from a), and also seems to } \\
\text { encompass more aspects of their work - thus a TP. } \\
\text { (D } \sqrt{ } \sqrt{ } ; \text { B } \sqrt{ } \sqrt{ } \text {; RS, } \sqrt{ } \sqrt{ } \text { ) }\end{array}$ \\
\hline
\end{tabular}


Note: Mezirow's OTL classification: TMS=Transformation in Meaning Scheme, TMP= Transformation in Meaning Perspectives. Hoggan's classification: Ont. = Ontology; Beh. = Behaviour; Epist. = Epistemology, and Wv = Worldview. Scale: $(\sqrt{ } \sqrt{ }=$ highly observed); $(\sqrt{ } \sqrt{ }=$ moderately observed $)$ and $(\sqrt{ }=$ less observed $)$ : $D=$ Depth; $B=$ Breadth; and $R S=$ Relative stability. 
their work to stimulate people to respond and think more deeply about fairness and the 'sublime' (those details can be found in the Supplementary Materials transcripts).

It is noteworthy that the data produced some examples of TLOs reported by a third party, and/or noted via behaviours (Tables 1 and 2: marked with ${ }^{* *}$ ) because the literature reports such scarcity of such objective data that one author has suggested that TLOs might not even exist at all (Newman, 2012).

\subsection{Triangulation: allusions to candidate $T L$ processes}

After finding clear evidence of specific TLOs related to the WeValue InSitu event, the interview transcripts were re-analysed for allusions to any sub-processes in the event which the participants perceived to be linked to those TLOs. For example, "...it created a space where we could reflect on what additional elements need to be considered .... ". This was done for triangulation and counter-argument checking of the TLOs found: a cross-check to confirm linkage to the actual event and not something extraneous, and also as an exploration to provide insights on possibly critical sub-processes that could be studies further in the future. A total of 14 comments were found, and nature of the sub-processes alluded to were found to be consistent with descriptions of all ten of Mezirow's TLT processes. Data extracts and coding summaries are given in Appendix $\mathrm{C}$.

Besides supporting the TLO allocations made, these findings support the concept that Mezirow-type processes were likely taking place, linked to the specific TLOs reported. This is encouraging since it implies that further future studies on the inner details of the WeValue InSitu events themselves are likely to provide direct evidence of links to the TLOs produced, and this is a major goal and challenge in the field of TL at the moment (Taylor and Snyder, 2012). The data here provides formative results for such future studies.

\section{Discussion}

\subsection{Confirmation and implications of reliable production of TLOS}

The data, summarised in Tables 2,3, and Appendix B, show unambiguously that in this case the WeValue InSitu event produced four outcomes which have a 'formal' Transformational Learning nature, against the classifications of Mezirow (1991). The data also yielded classification by Hoggan's (2015) typology and ratings of breadth, depth and relative stability. Furthermore, as given in Appendix A, there were many mentions in previous journal publications of similar, albeit informal, reports of TLOs from WeValue processes, which suggests - not a proof - that the process might reliably produce TLOs. In fact, new studies are now confirming this hypothesis: an experimental study of four village committees in Botswana with one control found TLOs resulting from WeValue InSitu (Sethamo et al., under review), and studies of students in China, and a research administrators' group in the UK. The WeValue InSitu is a standard process (when led by a specialist facilitator): the confirmation in this paper that its outcomes are formally 'transformative learning' in nature means that there now exists a 'pedagogical laboratory' tool which can be used for systematic studies of TL outcomes, processes and conditions. Calls for more research - and systematic research - into TL 
outcomes, processes and conditions have been strongly made for many years, especially in review articles (Taylor (2008); Taylor \& Snyder (2012); Aboytes \& Bart (2020)) where the metaanalysis across works has highlighted the lack of significant progress in any conceptual theorybuilding that could lead to prescriptive modelling.

One type of implication of this finding is that, with WeValue as a reliable method of 'producing' TLOs, different groups of similar types could be taken through the process, including the pre- and post-interviews, and causal links could be revealed between the TLOs, to the TL sub-processes that had occurred in each WeValue InSitu event. This would involve the 'opening' of the 'black box' of the WeValue InSitu process: the discussions within it themselves being recorded and transcribed, and analysed line by line to understand what sub-processes were present, how to classify them, and their connection if any to Mezirow's ten processes. Furthermore, the transformative learning 'conditions' could be systematically explored through modifications to the conditions of the process such as the group relationships, or power structures, or topic they had in common, to develop a better understanding of their impact on the TL and TLOs. This is important, because there have been repeated reports of a lack of clarity in understanding of what TL looks like in practice, and indeed which aspects of any practice contributed to particular TLOs (e.g. review of Taylor \& Snyder, 2012). Studies have already started on several of these strands of work, and both sub- and micro-processes seem to be emerging with strong links to Polanyi's Personal Knowledge Theory (ref), and, separately, Nonaka's Knowledge Management Theory (ref). Preliminary results suggest the WeValue InSitu process may eventually be able to show a link between those theories, and Mezirow's Transformative Learning Theory. The potential contributions to academic knowledge are thus quite significant for linkages to established systems of knowledge, and interesting because they would also have implications in practice.

Applications in environmental sustainability are already being trialled. For example, using WeValue InSitu to trigger locally-nuanced TLOs of village committees towards Local Climate Change Adaptation Plans in Botswana (Sethamo 2019), and to mobilise village counsellors in Nigeria in ecosystems services protection. In education, trials are taking place in the UK, Nigeria, and China to document the impacts on individuals (researchers, teachers, and teaching assistants respectively), and the results are being analysed against standardised benefits expected for mentoring programs (Castanheira 2016). The WeValue InSitu approach will never be a 'silver bullet' alternative or method for all circumstances where TLOs are desired, but it will be useful in a wide range of scenarios - which has yet to be scoped. Some known limitation are that it works best for groups that already have history of doing things together (actions); it works more strongly in small groups of 3-10 people but can be used effectively up to 25; the materials need to be prepared in the local language; the current version includes crystallisation but not nudging, and the ethics of consequences of either of these need to be considered for each group in advance.

\subsection{Other significant findings: range and strength of TLOs}


In this particular case study, the number of TLO types produced is surprisingly large. The recent systematic literature review of Aboytes \& Barth (2020) which included 83 papers using TL theory as a main framework, found that the TLOs reported in separate studies could be described in five types, which we find very useful: i) new skills; ii) reconstruction of values and perspectives; iii) new self-awareness and integrated identity; iv) complex thinking; iv) social learning - yet our one case seems to have produced all five types. They seem to start with a reconstruction of perspectives, then a new self-identify and social learning (together), then complex thinking leading to new skills. For example, the team previously had no clearly defined communication strategy, but as a result of the critical reflexivity developed in the WeValue InSitu event about their work (see Post-event Int.1, SM:SM: Line 220-225), they were able to develop new capacities: "the team will do things differently, as an outcome of this event. Very specifically, in terms of strategic communications, because we have created in effect, a blueprint. An example of gaining significant self-awareness and better understanding of 'what they do' was: “....(we) understand more clearly as a group WHO we are... therefore it [WeValue InSitu] helped us to articulate what is it at the heart of our project... (Post-Int.1; SM:SM "C"; lines 47-48; 50-51; 64-67). There was also a clear sense of future-casting: the changes in perspectives were already making them think about the future: "I feel this has created a framework by which we can go forward and hold ourselves to account and inspire ourselves on the other hand to strive further...." (Post int.1, SM:SM: line 240-243). It will be interesting for further studies to determine whether all five types are commonly produced by WeValue Insitu, and the relationships between them. This will help pinpoint which are more foundational than the others, and thus might deserve prioritisation in ESD or sustainability learning for field projects to be more effective.

Another discussion point is that the evidence provided by our data to support the TLO identification was surprisingly strong - four strands and each with pre-event and several postevent statements that are linked. This is in contrast to the commonly-reported struggles to identify and difficulties in evaluating TLOs, e.g. as summarised in Aboytes \& Barth (2020) who also refer to the "unpredictability and subjectivity" of the TLOs. Taylor's (2000) review stated that "a significant limitation found...has been the lack of reliability in identifying a change in meaning schemes and/or meaning perspective" that might have occurred. It seems possible that one reason our TLO evaluation was so effective is that there was no presumption as to what domain it would fall in: the pre- and post-event interviews simply provided scope for participants to make contextual statements around 'the things that are important to them' as group members. This is consistent with the paradigm used: WeValue InSitu is designed to crystallise the local shared values-in-action, but not to 'nudge' participants towards particular reflections or considerations. (However, a variation process could be devised to do that in the future.) On the one hand this means the TL that is occurring is related to a complex 'envelope' of locally-grounded reflections of the group on many topics which could be complicated to disentangle: on the other hand, this means that outcomes of the reflections are of intimate relevance to the team, and thus inherently more likely to be transformational. Regardless of the exact reason for the strength of the TLO evidence found, the WeValue InSitu as a strong method to identify and evaluate TLOs - 
contributing to Aboytes \& Barth's (2020) conclusion of, "a need for better methods...that can provide insights into...outcomes of transformative sustainability learning."

\subsection{Durable and more-objective learning}

The particular case studied here produced durable TLOs with long-term influence, and indeed, as shown in Table 3, one TLO continued to expand into a wider Transformation of Perspective. This was an incidental finding, but important to the field because although a clear call was made to report and grade longevity of influence (Hoggan, 2015), no evidence seems to have been reported which is as clear as in this work. Furthermore, Taylor (2015) pointed out that existing understanding was limited concerning tangible impacts of fostering transformative learning: in this study their evolution over time can be traced from reflection, increased selfawareness, discourse within group members, and development of new methods and practices

\section{Conclusion}

This in-depth case study has produced data which can clearly and systematically demonstrate the transformative learning nature of the outcomes of a process previously unknown to TL researchers - the WeValue InSitu process. The research design allowed preand three sets of post-event interview data to be compared, and the richness of that data led to multiple links to four TLOs to be extracted. They were all classified as transformations of meaning schemes, but one showed evolution over time to impact on wider meaning schemes, leading to a transformation of perspective. A review here of previously published studies of the WeValue InSitu process identified many examples of TLOs mentioned but not described as such, which is suggestive that the process can, as is now claimed, regularly produce TLOs. (Although in principle a series of predictive studies should now be undertaken to demonstrate the reliable production of TLOs, this has been done while the current study was prepared, and eight further cases demonstrated.) Together, these findings suggest that the WeValue InSitu process can be used as a 'laboratory' for systematic studies of TL, TLOs and the conditions producing them - an opportunity that has been called for in past and recent review papers.

The implications of this finding are far-reaching, providing a new research agenda, although with limitations. A major limitation is that the process works best with groups of participants who have worked together or experiences together, and only up to 25 people at a time (less is better). Others are that the process takes at least 2.5 hours, requires a specialist trained facilitator, and needs materials to be prepared in the local language. Applications which can accommodate those limitations include: the mobilisation of village groups// local governance officers// school managers// environmental groups// community-based organisations, towards more focussed, specific, action-linked visions developed from an increased self-awareness and enhanced group identity. The new focus might, or might not, include themes which are directly considered 'sustainability', but at the least their 'voice' and ability to crystallise local shared values will have been enhanced, and that is itself often considered an element of sustainability.

Besides using the WeValue InSitu process as a 'black box' to produce TLOs as above, it can be used for systematic studies of transformative learning processes, their links to TL outcomes, and the impact of variations in TL conditions. The first step is recording, transcribing 
and analysing the inside processes. Work has started on this, and it seems likely that the microprocesses revealed can then be linked strongly to Mezirow's ten TL processes. If so, then this means there is a clear pathway to causally link explicit TL processes to explicit TL outcomes. Series of participant groups can then be taken through the process, to map causal links, and variations in them. For example, groups of school teachers in a given school, such as by subject area, could be taken through the process thus producing TLOs of value to the school in terms of e.g. a better focus on the links of sustainability to their teaching content and approaches. But the variation of the groups will allow variations in TL-TLO linkages to be investigated. The detailed learning conditions can also be varied, such as the materials used, the emphasis on the disorienting dilemma, the mitigation of the inherent power structures, the context emphasised. The implication is that an integrated and prescriptive model of transformative learning can be built up, which will provide generalisable concepts that can be transferred beyond several of the limitations of the WeValue InSitu process.

Funding: This research did not receive any specific grant from funding agencies in the public, commercial, or not-for-profit sectors. 


\section{Appendix A}

\section{A systematic review of publications of WeValue InSitu approach reporting outcomes with TL-like nature}

In order to provide an indication of whether the production of TL-like outcomes is spurious or common in the WeValue approach, a systematic review was carried out 2006-2019 using the search terms "WeValue" OR "ESDINDS" in Science Direct. (ESDINDS was a prototype version of WeValue).

Even though 'transformational' effects were not the focus of any of the studies, and they were thus not described in great detail, it was possible to clearly identify eight case examples in five references. Some were via self-reports, but others included third-party observations, which are rare in mainstream TL literature and thus valuable. Categories of Epistemological, Ontological, and Behaviour types could be identified.

Reports of TL-like outcomes from WeValue/ ESDINDs events. 8 examples were found in five references, including self-reports and observations, of Epistemological, Ontological, and Behaviour types.

Table A1. Evidence from publications in the systematic literature review of WeValuebased studies, of transformational-like outcomes reported.

\begin{tabular}{|c|c|c|c|c|c|}
\hline & $\begin{array}{l}\text { Case studies with } \\
\text { reported TL-like } \\
\text { outcomes }\end{array}$ & $\begin{array}{l}\text { Extracts of references to } \\
\text { transformative moments }\end{array}$ & TLO gained & $\begin{array}{l}\text { Mode } \\
\text { of } \\
\text { meas } \\
\text { ureme } \\
\text { nt }\end{array}$ & $\begin{array}{l}\text { Refer- } \\
\text { ence }\end{array}$ \\
\hline 1 & $\begin{array}{l}\text { The people's } \\
\text { Theatre (PT). An } \\
\text { Art promotion } \\
\text { group. } \\
\text { (Germany). }\end{array}$ & $\begin{array}{l}\text { "Both the orientation program for } \\
\text { volunteers and the way in which the } \\
\text { goals of PT's work are } \\
\text { communicated to new schools, have } \\
\text { been restructured to centre around } \\
\text { values" }\end{array}$ & $\begin{array}{l}\text { Transformati } \\
\text { on in the } \\
\text { value } \\
\text { consciousnes } \\
\text { s of the team. } \\
\text { (Ontological } \\
\text { TLO) }\end{array}$ & $\begin{array}{l}\text { Obser } \\
\text { vation }\end{array}$ & $\begin{array}{l}\text { Burford } \\
\text { et. al., } \\
\text { (2013) }\end{array}$ \\
\hline 2 & $\begin{array}{l}\text { International } \\
\text { Federation of Red } \\
\text { Cross and Red } \\
\text { Crescent Societies } \\
\text { (IFRC). A } \\
\text { humanitarian Non- } \\
\text { profit organization. } \\
\text { (Sierra Leone) }\end{array}$ & $\begin{array}{l}\text { "The IFRC representative was able } \\
\text { to communicate the expectations } \\
\text { and goals of the YABC initiative } \\
\text { more effectively to a Government } \\
\text { department, which has accordingly } \\
\text { modified the way in which it } \\
\text { understands and communicates the } \\
\text { concept of behavior change" }\end{array}$ & $\begin{array}{l}\text { Transformati } \\
\text { on in the way } \\
\text { that the IFRC } \\
\text { members } \\
\text { understand, } \\
\text { communicate } \\
\text { concepts } \\
\text { about goals, } \\
\text { expectations. }\end{array}$ & $\begin{array}{l}\text { Obser } \\
\text { vation }\end{array}$ & $\begin{array}{l}\text { Burford } \\
\text { et.al., } \\
\text { (2013) }\end{array}$ \\
\hline
\end{tabular}




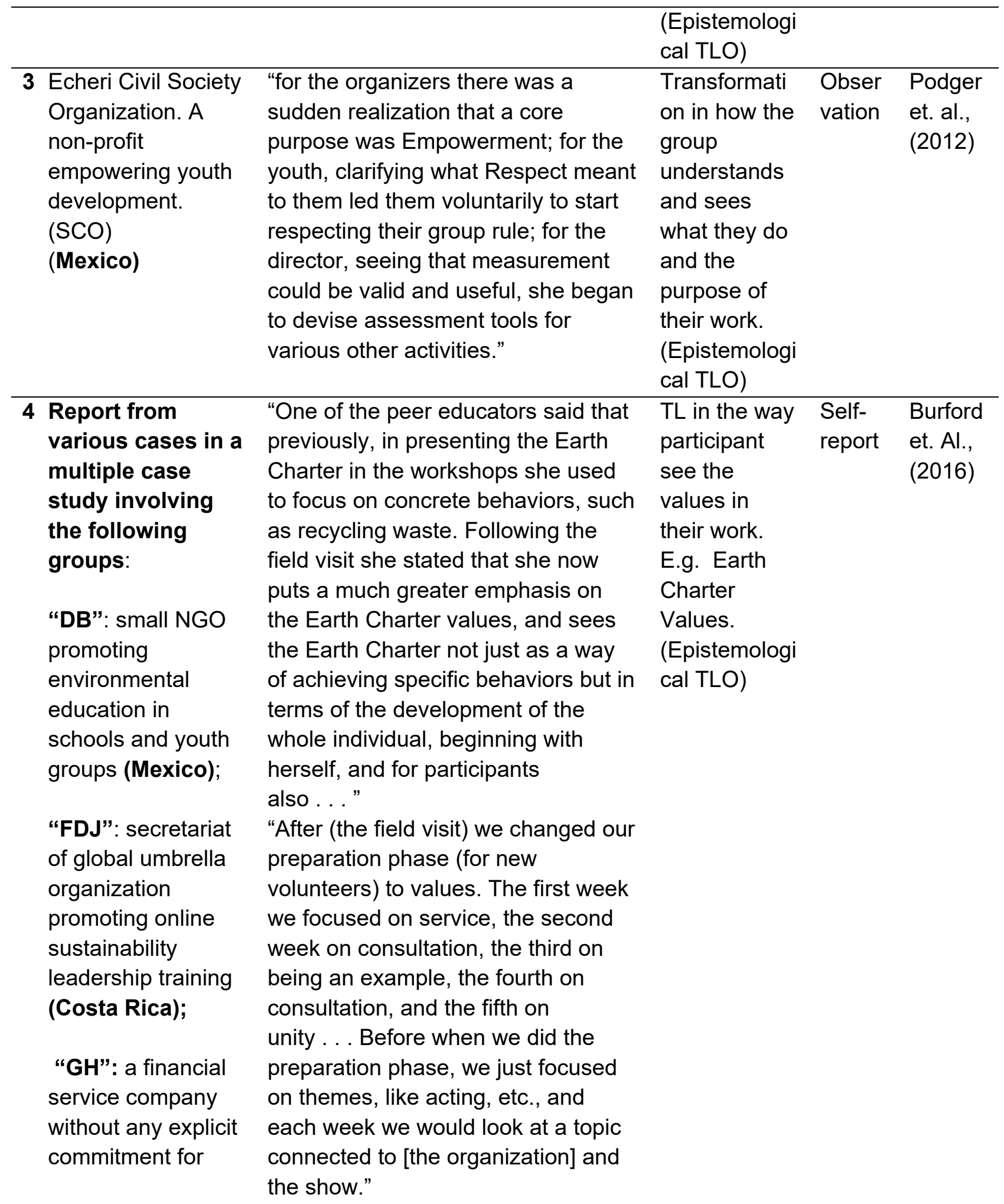




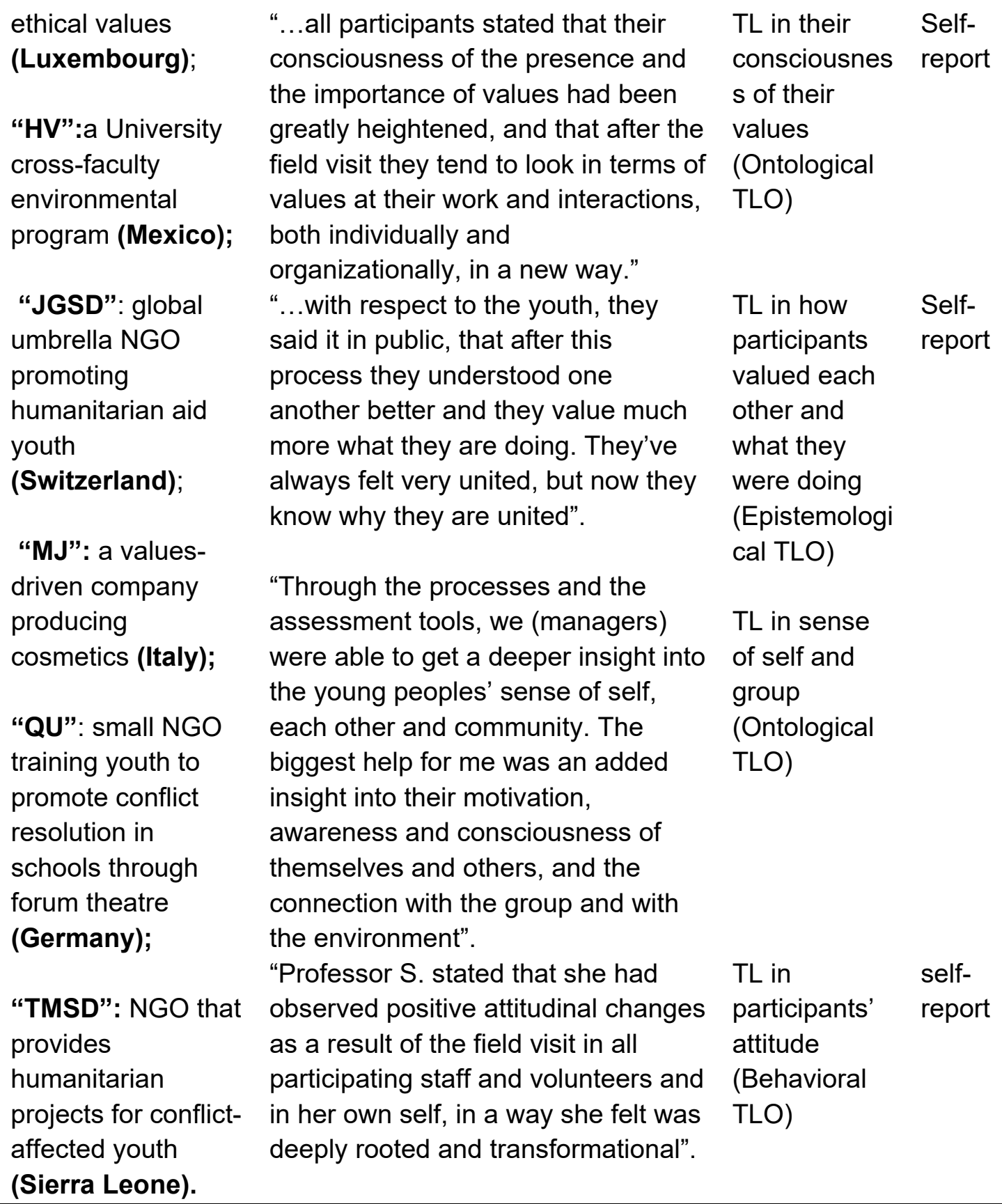




\begin{tabular}{|c|c|c|c|c|}
\hline $\begin{array}{l}5 \text { Multiple Cases } \\
\text { involving four } \\
\text { Village } \\
\text { Development } \\
\text { Committees. } \\
\text { (Botswana) }\end{array}$ & $\begin{array}{l}\text { "It helps us map the way forward. } \\
\text { The framework helps to open our } \\
\text { eyes to see exactly what we are } \\
\text { doing. At times you are busy trying } \\
\text { to achieve something only to find } \\
\text { that you are just in the dark, so this } \\
\text { framework opens our eyes". }\end{array}$ & $\begin{array}{l}\text { TL in how } \\
\text { participant } \\
\text { can } \\
\text { perceive/see } \\
\text { what they are } \\
\text { doing. } \\
\text { (Epistemologi } \\
\text { cal TLO) }\end{array}$ & $\begin{array}{l}\text { Self- } \\
\text { report }\end{array}$ & $\begin{array}{l}\text { Setham } \\
\text { o et. } \\
\text { al., } \\
(2019)\end{array}$ \\
\hline
\end{tabular}




\section{Appendix B}

Table B1. A further TLO found in this case study. Thus, a continuation of the information in Table 2, included here for comprehensive reporting, but excluded from Table 2 as another, similar example is already included there and a long table would interrupt the storyline.

\section{Transformation in SEEING PATHWAYS. (TMS; Epist.)}

[Pre-E] "We are engaged on a journey where we're not entirely clear where the end is, the shape of the journey, but we know we're on it and we're enjoying it and we're purposeful in terms of our engagement...." (Pre-FG; SM:1; C; line 62-66)

[Post-E] (a) "Connecting together in some form or another, so, less muddled, umm much clearer pathways between you know, getting from $a$ to $b$ as far as why and what the work is about..." (Post-Int.1; SM:3; “J”; line 103-112)

[Post-E] (b) "Yeah, I think so, yeah, definitely. I mean that's the impression I got. Yep, just to have a clearer understanding gives you a clearer pathway to pursue. You're not second-guessing stuff, ..." (Post-Int.1; SM:3; J; line 187-189)

The participants do not know the direction of their work nor the pathways they use to function.

Evidence that Participant can now see the pathways they adopt in doing their work.

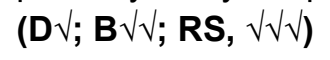

[Post-E] (c) "F: "Would you say that there was a meaningful shift in perspective"?

J: "Yeah, yeah ... Um, your uh, your corridor of understanding had been, made more, more defined. So, because of this, yeah definitely a perspective...um, not so much a perspective shift, but a um, a sort accurate triangulation of what's happening, therefore your end point will be more accurate. Yeah. So, I suppose that is a perspective shift, but only a few degrees..." (Post-Int.1; SM:3; J; Lines 243-247) 


\section{Appendix C}

Table C1. Allusions from post-event interviews of participants to their perceptions of sub-processes which influenced their transformations of meaning schemes Mezirow (1991).

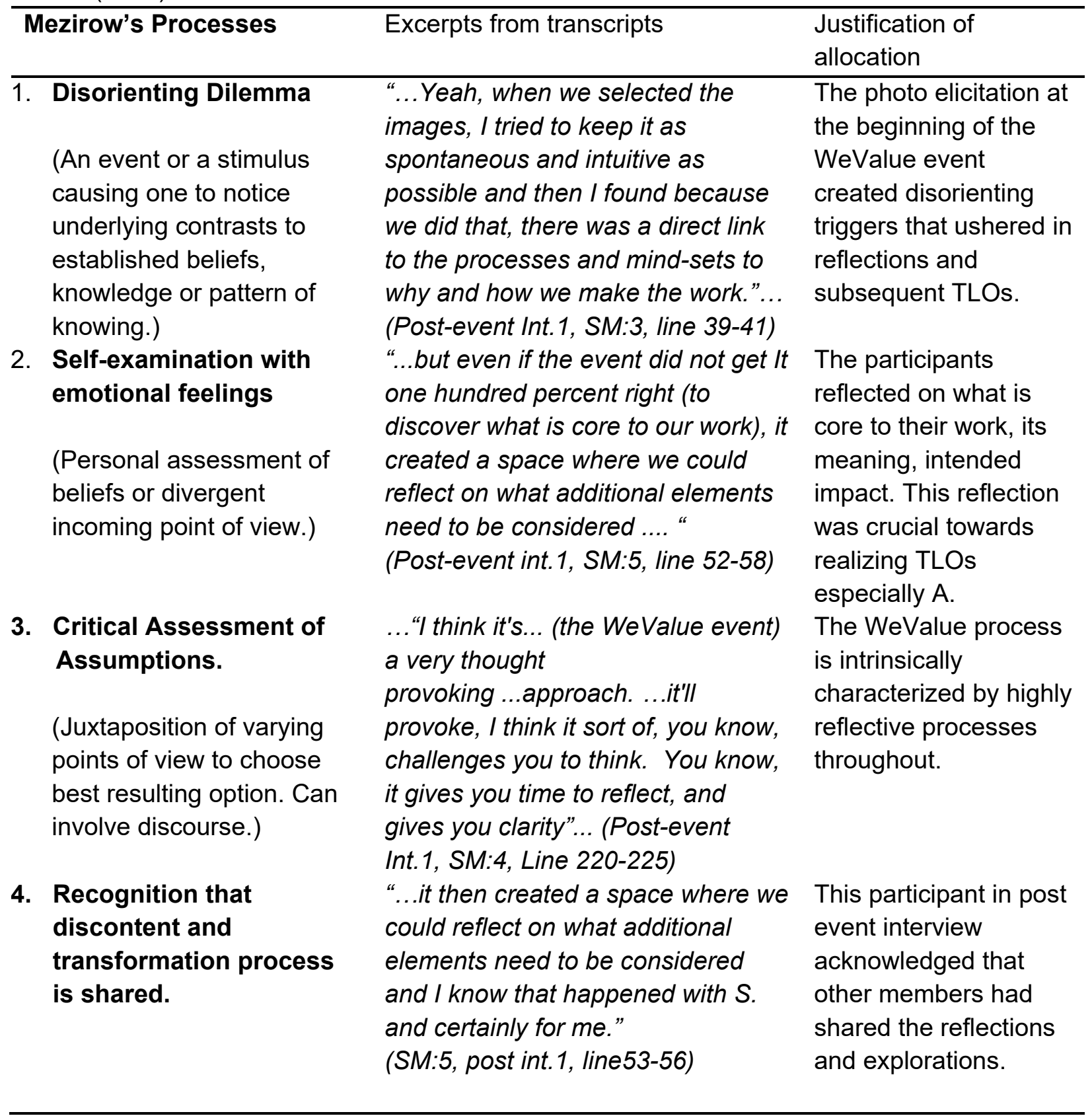




\section{Exploration of options for new roles, relationships and actions}

\section{Planning a course of actions}

\begin{abstract}
"It did, it actually got me thinking about new projects that I'm working

on, and adopting this cyclical
\end{abstract} pattern and how everything interacts. (Post. Int.1, SM:3, line 144-147)

"The team will do things differently, as an outcome of this event. Very specifically, in terms of strategic communications, because we have created in effect, a blueprint. ... I feel this has created a framework by which we can go forward and hold ourselves to account and inspire ourselves on the other hand to strive further..." (Post int.1, SM:5, line 240-243)

"I think we are going to produce a timeline..."

(Post int.2, SM:6, line 111)

7. Acquiring knowledge and skills for implementing one's plans

\section{Provisional trying of new Roles}

9. Building competence and ditto self-confidence in new roles and relationship

\section{Re-integration of New} Learnt Frame of reference or Meaning Scheme
: "I think her methodologies are becoming more efficient. She seems to think clearer and faster..." (Post-Int. 2, SM:6, J, lines 62-63) ditto

"...So I just like made the map by myself, so that is pretty cool and it was done in a few days it became a little bit more complex ... (unclear) but the map made it much more complex." (Post int.2, SM:6, line 9195)
A clear statement of exploration of new perspectives.

Clear statements of planning actions.
One participant alludes to another's new skills...

Allusion to trying new roles...

Allusion to becoming more confident.

The learnt new behaviour is seen here being already put in use by respondent $\mathrm{J}$. 


\section{References}

Aboytes, J. G. \& Barth, M., 2020. Transformative learning in the field of sustainability: a systematic literature review (1999-2019). Int. J. of Sust. in High. Educ. 21(5), doi:10.1108/IJSHE-05-2019-0168

Brunstein, J., King, J., 2018. Organizing reflection to address collective dilemmas: engaging students and professors with sustainable development in higher education. J. Clean. Prod. 203, pp.153-163. https://doi.10.1016/j.jclepro.2018.08.136

Brunstein, J., Sambiase, M.F., Kerr, R.B., Brunnquell, C. and Perera, L.C.J. (2019), "Sustainability in finance teaching: evaluating levels of reflection and transformative learning”, Soci. Resp. J, 16(2), pp. 179-197.

Burford, G., Hoover, E., Stapleton, L., Harder, M., 2016. An unexpected means of embedding ethics in organizations: preliminary findings from values-based evaluations. Sustainability.. 8, (7) 612. doi:10.3390/su8070612

Burford, G., Velasco, I., Janouskova, S., Zahradnik M., Hak, T., Podger, D., Piggot, G., Harder, M., 2013. Field trials of a novel toolkit for evaluating intangible values-related dimensions of projects. Eval. and Progr. Plan. (26)1-14. doi:org/10.1016/j.evalprogplan.2012.04.005

Burgelt, P., Morgan, M., Julian, R., Bedford, D., 2018. Migrating - a transformative process towards actualizing authentic selves and lives. In: Welch, M., Marsick, V., Holt, D. (Eds.), Building Transformative Community: Exacting Possibility in Today's Times. New York: Columbia University.

Castanheira, P., 2016. Mentoring for educators' professional learning and development: a metasynthesis of IJMCE volumes 1-4. Int. J. of Ment. and Coach. in Edu, 5(4), pp. 334-346, doi: 10.1108/IJMCE-10-2015-0030

Didham, R. J., Ofei-Manu, P., 2013. Advancing education as a goal for sustainable development. IGES Issue Briefs on SDGs Series. Hayama, Japan

Diduck, A., Sinclair, J., Hostetler, G., Fitzpatrick., 2012. Transformative learning theory, public involvement, and natural resource and environmental management. J. of Envi. Plan. and Manag. 55(10), 1311-1330. doi:10.1080/09640568.2011.645718.

Dirkx, J. M., Espinoza, B. D., Schlegel, S., 2018. Critical reflection and imaginative engagement: towards an integrated theory of transformative learning. Paper presented at the Adult Education Research Conference, Victoria, BC., Canada. Retrieved from http://newprairiepress.org/aerc/2018/papers/4. 20/04/2018

Greig, A., Priddle, J., 2019. Mapping students' development in response to sustainability education: a conceptual model. Sustainability, 11(16), p.4324. doi:10.3390/su11164324.

Harder, M. K., \& Burford, G., 2018. Measuring Intangible Values: Rethinking How to Evaluate Socially Beneficial Actions. (Routledge Studies in Sustainability). Routledge.

Hoggan, C., 2015. Transformative learning as a metatheory: definition, criteria, and typology. Adult Educ. Q., 66, 57-75. doi:10.1177/0741713615611216

Leal Filho, W., Raath, S., Lazzarini, B., Vargas, V.R., De Souza, L., Anholon, R., Quelhas, O.L.G., Haddad, R., Klavins, M., Orlovic, V.L., 2018. The role of transformation in 
learning and education for sustainability. J. of Clean. Prod. 199, 286-295. doi:10.1016/j.jclepro.2018.07.017

Mezirow, J., 1991. Transformative Dimensions of Adult Learning. Jossey-Bass.

Mezirow, J., 2000. Learning to think like an adult. In: Mezirow, J., and Associates, (Ed), Learning as Transformation: Critical Perspective on a Theory in Progress. San Francisco, CA: Jossey-Bas.pp. 3-34

Moreno, J.M., Noguchi, L.M., Harder M.K., 2017. Understanding the process of community capacity-building: a case study of two programs in Yunnan Province, China. World Dev. 97:122-137. https://doi.org/10.1016/j.worlddev.2017.04.005

Najjar, D., Spaling, H., Sinclair, J., 2013. Learning about sustainability and gender through farmer field school in Taita Hills, Kenya. Int. J. of Educ. Dev., 33(5), 466-475. doi:10.1016/j.ijedudev.2012.06.004

Newman, M., 2012. Calling transformative learning into question: Some mutinous thoughts. Adult Educ. Q., 62(1), 36-55. doi:10.1177/0741713610392768

Ofei-Manu, P., Didham, R.J., 2018. Identifying the factors for sustainability learning performance. J. of Clean. Prod. 198, pp.1173-1184.

O'Sullivan, E., 2008. Finding Our Way in the Great Work. J. of Transf. Educ., 6(1) pp. 27-32

Papenfuss, J., Merritt, E., 2019. Pedagogical Laboratories: A case of transformative sustainability education in an ecovillage context. Sustainability. 11(14), doi:10..3390/su11143880

Pisters, S.R., Vihinen, H., Figueiredo, E., 2019. Place based transformative learning a framework to explore consciousness in sustainability initiatives. Emotion, Space and Society, 32, p.100578

Podger, D., Hoover, E., Burford, G., Hak, T., Harder, M., 2016. Revealing values in a complex environmental program: a scaling up of values-based indicators. J. of Clean. Prod. 134. pp. 225-238 http://dx.doi.org/10.1016/j.jclepro.2015.08.034

Podger, D., Velasco, I., Luna, C. A., Burford, G., Harder, M. K., 2012. Can values be measured? significant contributions from a small civil society organization through action research. Act. Res. 11(1), 8-30. https://doi.org/10.1177/1476750312467833

Podger, D., Piggot, G., Zahradnik, M., Janoušková, S., Velasco, I., Hak, T., Dahl, A., Harder, M. K., 2010. The Earth Charter and the ESDinds Initiative: developing indicators and assessment tools for civil society organizations to examine the values dimensions of sustainability projects. J. Edu. Sus. Dev. 4(2), 297-305. https://doi.org/10.1177/097340821000400219.

Probst, L., Bardach, L., Kamusingize, D., Templer, N., Ogwali, H., Owamani, A., Mulumba, L., Onwonga, R., Adugna, B.T., 2019, "A transformative university learning experience contributes to sustainability attitudes, skills and agency”, J. of Clean. Prod. 232, pp. 648656 
Sethamo, O., Masika, R., Harder, M. K., 2019. Understanding the role of crystallizing local shared values in fostering effective community engagement in adaptation planning in Botswana. Clim. Dev. 1-9. https://doi.org/10.1080/17565529.2019.1639488.

Sharpe, J., 2016. Understanding and unlocking transformative learning as a method for enabling behavior change for adaptation and resilience to disaster threats. Int. J. of Dis. Risk Red. (17) 213-219

Taylor, E., 1998. The theory and practice of transformative learning: a critical review. ERIC Clearinghouse on Adult, Career, and Vocational Education, Center on Education and Training for Employment, College of Education, the Ohio State University. ASIN: B000110N32

Taylor, E., 2000. Analyzing research on transformative learning theory. In: Mezirow, J. and Associates (Ed), Learning as transformation: Critical Perspective on a Theory in Progress. San Francisco, CA: Jossey-Bas. 285-328

Taylor, E. W., 2008. Transformative learning theory. New Direct. for Adult Cont. Educ. 119, 515. $h$ ttp://dx.doi.org/10.1002/ace.301

Taylor, E. W., Snyder, M., 2012. A critical review of research on transformative learning theory (2006-2010), In: Taylor, E., Cranton, P. (Eds.), The Handbook of Transformative Learning Theory; Research, Theory and Practice. Jossey-Bas, San Francisco, CA, pp. 37-55.

Taylor, E., 2015. Teacher transformation: a transformative learning perspective. Italian J. of Educ. Res. ISSN 2038-9744

UNESCO, 2017. Education for Sustainable Development Goals: Learning Objectives. 7, place de Fontenoy, 75352 Paris 07 SP, France. ISBN 978-92-3-100209-0 